\title{
Seasonal controls on snow distribution and aerial ablation at the snow-patch and landscape scales, McMurdo Dry Valleys, Antarctica
}

\author{
J. W. Eveland ${ }^{1}$, M. N. Gooseff ${ }^{1, *}$, D. J. Lampkin ${ }^{2, * *}$, J. E. Barrett ${ }^{3}$, and C. D. Takacs-Vesbach ${ }^{4}$ \\ ${ }^{1}$ Department of Civil \& Environmental Engineering, Pennsylvania State University, University Park, PA 16802, USA \\ ${ }^{2}$ Department of Geography, Pennsylvania State University, University Park, PA 16802, USA \\ ${ }^{3}$ Department of Biological Sciences, Virginia Tech, Blacksburg, VA 24061, USA \\ ${ }^{4}$ Department of Biology, University of New Mexico, Albuquerque, NM 87131, USA \\ * now at: Department of Civil \& Environmental Engineering, Colorado State University, Fort Collins, CO 80523, USA \\ ** now at: Department of Atmospheric and Oceanic Science, University of Maryland, College Park, MD 20742, USA
}

Correspondence to: J. W. Eveland (jwe137@gmail.com)

Received: 12 July 2012 - Published in The Cryosphere Discuss.: 12 September 2012

Revised: 19 April 2013 - Accepted: 2 May 2013 - Published: 11 June 2013

\begin{abstract}
Accumulated snow in the McMurdo Dry Valleys, while limited, has great ecological significance to subnivian soil environments. Though sublimation dominates the ablation process in this region, measurable increases in soil moisture and insulation from temperature extremes provide more favorable conditions with respect to subnivian soil communities. While precipitation is not substantial, significant amounts of snow can accumulate, via wind transport, in topographic lees along the valley bottoms, forming thousands of discontinuous snow patches. These patches have the potential to act as significant sources of local meltwater, controlling biogeochemical cycling and the landscape distribution of microbial communities. Therefore, determining the spatial and temporal dynamics of snow at multiple scales is imperative to understanding the broader ecological role of snow in this region.

High-resolution satellite imagery acquired during the 2009-2010 and 2010-2011 austral summers was used to quantify the distribution of snow across Taylor and Wright valleys. Extracted snow-covered area from the imagery was used as the basis for assessing inter-annual variability and seasonal controls on accumulation and ablation of snow at multiple scales. In addition to landscape analyses, fifteen $1 \mathrm{~km}^{2}$ plots ( 3 in each of 5 study regions) were selected to assess the prevalence of snow cover at finer spatial scales, referred to herein as the snow-patch scale. Results confirm that snow patches tend to form in the same locations each year with some minor deviations observed. At the snow-patch
\end{abstract}

scale, neighboring patches often exhibit considerable differences in aerial ablation rates, and particular snow patches do not reflect trends for snow-covered area observed at the landscape scale. These differences are presumably related to microtopographic influences acting on individual snow patches, such as wind sheltering and differences in snow depth due to the underlying topography. This highlights the importance of both the landscape and snow-patch scales in assessing the effects of snow cover on biogeochemical cycling and microbial communities.

\section{Introduction}

The McMurdo Dry Valleys are an ice-free polar desert on a continent otherwise covered almost entirely by ice. During the austral summer, ephemeral streams link alpine glaciers in the surrounding mountains of Taylor and Wright valleys to closed-basin lakes (Fountain et al., 1999). Mean annual air temperature ranges from $-15^{\circ} \mathrm{C}$ to $-30^{\circ} \mathrm{C}$; the wide range in annual air temperature stems from the variability in the frequency of strong wind events capable of elevating temperatures, especially during the winter months (Doran et al., 2002; Nylen et al., 2004; Speirs et al., 2010). Soils in the McMurdo Dry Valleys lack vascular vegetation and exhibit very low biological activity with simple food webs composed of microbes and several species of soil invertebrates (Wall and Virginia, 1999; Cary et al., 2010). However, these 
microbially dominated ecosystems are water limited, and the availability of liquid water has been shown to be a primary control over the distribution and activity of soil organisms (Kennedy, 1993; Barrett et al., 2008). Given the scarcity of liquid water, the interface between seasonal snow cover and subnivian soil may be a critical zone determining hydrological inputs to soils and resulting ecological processes.

Snow patches have the potential to influence subnivian soils in two ways: thermal insulation and the potential to provide moisture to those soils (Gooseff et al., 2003). While snowmelt is considered to contribute a minimal proportion to the snow ablation budget, the McMurdo Dry Valleys are a highly water-limited environment and otherwise negligible volumes of snowmelt are significant. Increases of soil moisture in subnivian soils relative to the neighboring dry soils have been observed by past studies in this region (Gooseff et al., 2003; Ayres et al., 2010). Additionally, snow cover has been shown to act as a thermal insulator by dampening temperature extremes (Walker et al., 1999; Schimel et al., 2004; Gooseff et al., 2003), and has been shown to influence biogeochemical cycling and microbial activity in subnivian soils for alpine and Arctic environments (Brooks et al., 1995, 1996; Brooks and Williams, 1999; Walker et al., 1999; Schimel et al., 2004; Edwards, 2007). Outside zones of enhanced geochemical and microbial activity provided by stream and lake margins (Zeglin et al., 2009), seasonal snow is the only potential source of moisture over a large portion of the landscape in the valleys. Additionally, melt from seasonal snow cover significantly contributes to the formation of water tracks, which connect landscape processes by transporting water, energy, and nutrients (Levy et al., 2011). This highlights the importance of snow-covered area with respect to landscape processes.

In the McMurdo Dry Valleys, seasonal snow accumulates during the austral winter primarily from aeolian sources transporting snow from the Polar Plateau. Seasonal snow tends to accumulate in topographic lees forming discontinuous patches, generally on the order of tens of meters in size (Gooseff et al., 2003). To understand the influence of seasonal snow patches on subnivian soils, it is necessary to understand the inter-annual variability of the magnitude of snow-covered area (landscape scale) and the precise locations of accumulated snow patches (snow-patch scale). Additionally, understanding temporal dynamics during the ablation season and the factors controlling ablation is also necessary. Analyzing the spatial and temporal patterns for two recent seasons, 2009-2010 and 2010-2011, through the use of high-resolution satellite imagery will serve to inform these processes at the snow-patch and landscape scales.

Measures of annual precipitation in the McMurdo Dry Valleys are limited, but range from 3 to $50 \mathrm{~mm}$ of snow water equivalent, depending on location (Fountain et al., 2009). Inter-annual variation in the magnitude of snow-covered area and the controls contributing to accumulation and ablations processes are not well known within the McMurdo Dry Val- leys. Most of the previous work on the subject of seasonal snow in the valleys has focused on point measurements of precipitation (Bertler et al., 2004; Fountain et al., 2009; Witherow et al., 2006). Since 1995, precipitation measurements have been recorded by the McMurdo Long Term Ecological Research program in addition to a multi-year continuous measurement of snowfall during the late 1960s and early 1970s (Keys, 1980; Bromley, 1985). Recent snowfall measurements have been several orders of magnitude greater than those recorded several decades ago, highlighting the interannual variability of snowfall and snow-covered area in the McMurdo Dry Valleys (Fountain et al., 2009). Assuming snow-covered area is directly proportional to precipitation, seasonal snow coverage should also exhibit a high degree of variability. However, if the source of accumulated snow is predominantly from aeolian redistribution, the variability of snow coverage may be less sensitive to local precipitation.

It may be expected that because the presence of snow patches appears to be associated with topographic lees and depressions, they will collect in the same locations every year. Presumably, the distribution of snow patches corresponds to the distribution of nivation hollows. In fact, the hypothesized ecological role of seasonal snow is predicated upon the assumption of snow patches forming in the same locations during each new accumulation season. Because the soil beneath and immediately adjacent to snow patches has the potential to facilitate the development of microbial communities, it is important to assess the temporal variability of snow at the snow-patch scale. For snow patches to promote enhanced biogeochemical cycling and the long-term influence of microbial communities, consistent annual accumulation of snow cover is important.

With respect to the landscape scale, previous analyses in the Dry Valleys have shown the distributions of snowcovered area with respect to elevation, slope, and aspect at peak accumulation generally correspond to the underlying topography (Eveland et al., 2013). This implies that snow is not preferentially distributed with respect to particular topographic parameters during peak accumulation at the landscape scale, and rather is distributed fairly ubiquitously during peak accumulation. Therefore, it is reasonable to expect the shape of these distributions to remain the same each season despite the large range of variation in magnitude of precipitation observed in the past. However, when ablation begins to accelerate, after peak accumulation, several factors may lead to year to year differences in ablation rates and late season patterns of snow-covered area. Previous analyses of high-resolution imagery from the 2009-2010 ablation season have shown elevation to be the strongest predictor of aerial ablation at the landscape scale in this region. In general, snow-covered area at higher elevations appears to be more persistent. Additionally, regions of unique microclimates display differences in aerial ablation with inland regions experiencing greater aerial ablation rates than coastal sites (Eveland et al., 2013). 


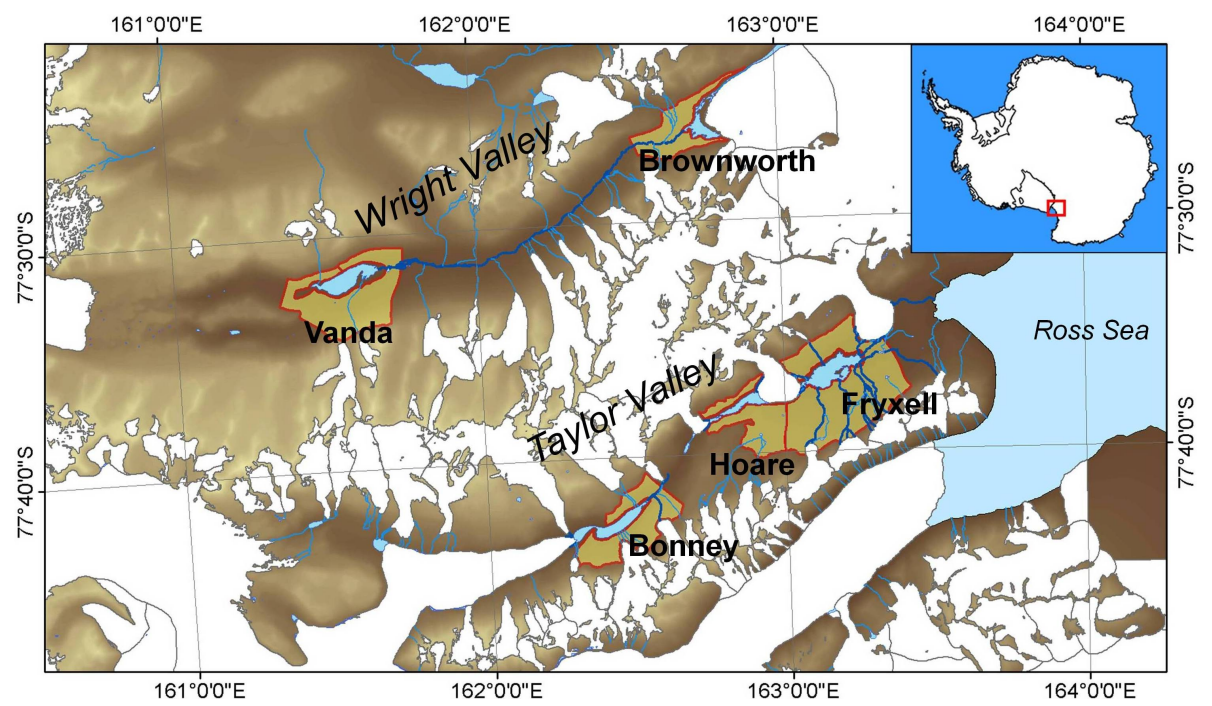

Fig. 1. Study regions are shown in the neighboring Taylor and Wright valleys in the McMurdo Dry Valleys region of Antarctica.

Other studies have examined the inter-annual variability of snow distribution and the controls on such spatial and temporal patterns (Deems et al., 2008; Erickson et al., 2005; Winstral et al., 2002). Additionally, local effects have been shown to have significant influence over the ablation of snow patches (Liston, 1995; Mott et al., 2012; Schirmer et al., 2011). These local effects are similar to what will be discussed with regard to controls on ablation at the snow-patch scale. However, the results presented here are unique to previous studies. While previous work on these topics has primarily been limited to alpine environments, the Dry Valleys are an environment with unique topography, climate, and distribution mechanisms. Also, the spatial resolution utilized in the ensuing analyses is much finer than what is typically used.

Our objectives are to assess seasonal controls on the accumulation and ablation of snow in the McMurdo Dry Valleys. Analysis of both the snow-patch (tens of meters) and landscape (tens of kilometers) scales and the linkages between these scales is needed to adequately characterize processes associated with snow-covered area and the implications such processes have towards local soils and hydrology.

\section{Methods}

\subsection{General methodology}

Analysis of seasonal snow within the McMurdo Dry Valleys was limited to neighboring Taylor and Wright valleys (Fig. 1). Within the valleys, five study regions were selected to analyze snow-covered area. These regions include the surrounding regions of Lake Fryxell, Lake Hoare, Lake Bonney, Lake Brownworth, and Lake Vanda. Detailed rationale and methods for delineating these specific regions can be found in Eveland et al. (2013). In short, each region represents an eastern, central, or western location within the valleys. The immediate surrounding areas of lakes and glaciers are excluded, and the delineated regions extend in elevation to a point in which slope increases significantly (i.e., where the valley floor ends).

High-resolution remotely sensed imagery acquired during the austral summers of 2009-2010 and 2010-2011 was utilized for comparing the seasonality of snow accumulation and aerial ablation, including QuickBird, WorldView-1, and WorldView-2 imagery of the DigitalGlobe constellation. Preprocessing, including orthorectification of imagery, was conducted by the Polar Geospatial Center, University of Minnesota. WorldView-1 imagery consists of a single panchromatic band, while QuickBird and WorldView-2 are multispectral platforms. For our analyses we only used data from the panchromatic bands $(448-924 \mathrm{~nm})$. The spatial resolutions of the panchromatic bands for QuickBird, WorldView1 , and WorldView- 2 are 60,50 , and $50 \mathrm{~cm}$ respectively. The satellites have revisit frequencies on the order of 1-2 times per week in Taylor and Wright valleys, but persistent cloud cover significantly reduces the frequency of available data. The frequency of available imagery is thus variable and averages approximately one image per two weeks. However, in some instances there are large data gaps in time, and in other instances images may be separated by only a few days. The dates of available imagery are presented in Fig. 2.

Using high-resolution imagery is necessary to capture the temporal evolution of the extent of individual snow patches, which may be as small as a few square meters. For our purposes, this makes these platforms ideal for analyzing snow-covered area. Previous to the austral summer of 2009, QuickBird and WorldView-1 imagery had been collected within the McMurdo Dry Valleys region since 2003, but only 


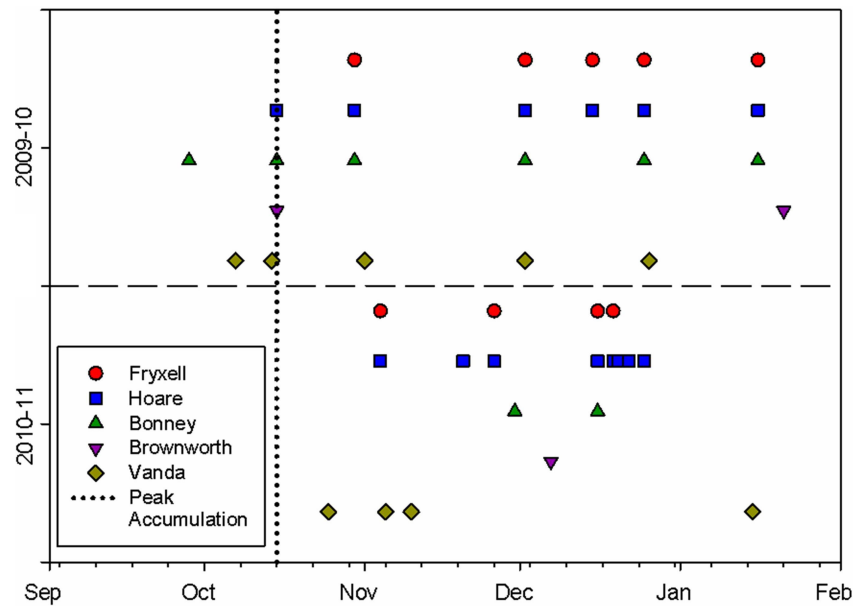

Fig. 2. Temporal resolution of sufficient quality images is variable. The dates of available imagery for each region during both seasons are shown. The horizontal dashed line separates the two seasons, and the vertical dotted line represents what is considered to be the time of peak accumulation. Circled symbols represent the images chosen to represent peak accumulation.

sporadically. Additionally, the available imagery set prior to 2009 has very limited spatial coverage. Aerial photography from the past several decades is also available. While some of the aerial photography has the necessary spatial resolution to resolve small snow patches, it does not have the temporal frequency or the broad spatial coverage to monitor aerial ablation throughout the valleys. Therefore, the austral summers of 2009-2010 and 2010-2011 are the first years when datasets of sufficient spatial and temporal resolution were available. Since this analysis is limited to only these seasons, and because previous measurements of precipitation have varied dramatically, it is unclear how this analysis reflects the range of variability in snow-covered area over longer time scales, but this study represents a necessary first step in quantifying the temporal and spatial evolution of snow patches in the Dry Valleys.

Analyses are conducted at two scales: the snow-patch scale and the landscape scale. For this discussion, the snowpatch scale refers to the range from a single snow patch to a collection of neighboring snow patches, approximately one square kilometer in area. The landscape scale refers to the scale tens of square kilometers and larger. This includes the five delineated regions (Fig. 1) as well as the valleys as a whole. The methodology for extracting snow-covered area from the high-resolution imagery is identical to that described in Eveland et al. (2013). In short, an edge detection algorithm uses spectral, spatial, and textural characteristics of each available image to isolate snow patches from the surrounding soil. A $30 \mathrm{~m}$ digital elevation model (DEM) is used to append characteristics of elevation, slope, and aspect to the snow patches for analysis at the landscape scale. It should be noted that the available DEM does not have a resolution

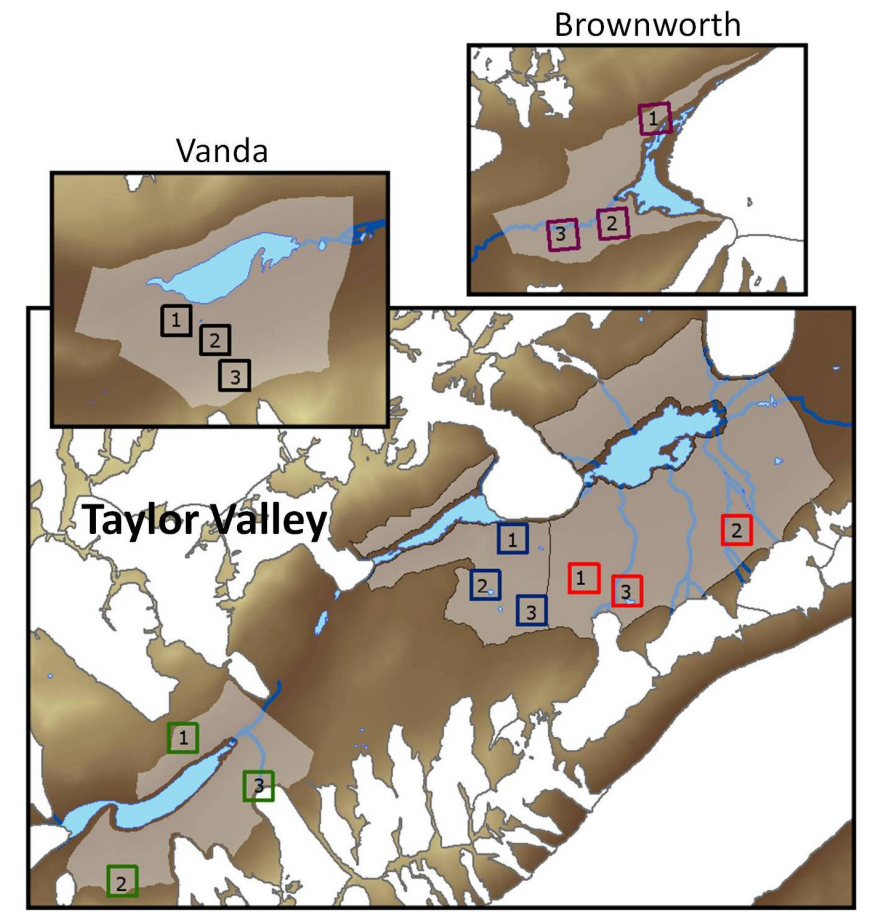

Fig. 3. Locations of randomly selected $1 \mathrm{~km}^{2}$ plots for assessing inter-annual variability of prevalence of snow at the snow-patch scale.

sufficient to resolve the nivation hollows in which individual snow patches form, nor can the fine-scale topography surrounding individual snow patches be resolved with the spatial resolution of this DEM.

\subsection{Snow-patch-scale analyses}

To determine the inter-annual variability of snow prevalence at the patch scale, the degree of overlap between the 2009-2010 and 2010-2011 seasons was quantified at a fine enough scale to investigate the snow-patch dynamics, but broad enough to contain dozens of snow patches. Three random $1 \mathrm{~km}^{2}$ plots were selected from each of the five defined regions (Fig. 1) in which snow-covered area was extracted. To randomly select the plots, numbers were assigned to each individual snow patch present during peak accumulation (dates found in Fig. 2) of the 2009-2010 season, and a random number generator was used to choose the snow patches that correspond to the centers of the 15 plots. In this manner, the likelihood of a $1 \mathrm{~km}^{2}$ region being selected increases for those regions with greater spatial snow cover. The locations of these plots are shown in Fig. 3.

Limitations in the orthorectification process at the landscape scale result in insufficient precision to determine precise snow patch locations. This fine-scale analysis thus requires two imagery sets (one from each season) for each of the 15 plots to be aligned to each other by using featurematching techniques. Fixed features, such as polygon cracks 
or large boulders, are used to align the images. Because these control points are less than ideal, some artifacts remain, introducing error into the analysis, but visual inspection suggests this error is minimized. Despite the artifacts that remain after aligning the images, the analysis enables investigating inter-annual snow-patch dynamics at fine scales.

Using GIS-based techniques, a vector dataset is produced that is the intersection of the 2009-2010 and 2010-2011 vector data of snow-covered area (SCA). The snow-covered area of 2009-2010 is used as a baseline, and the degree to which the snow-covered area of the 2010-2011 season co-locates is quantified. The intersection of the two seasons is spatially joined to the vector data of the 2010-2011 season. For each polygon in the 2010-2011 dataset, the proportion of that area that intersects with the previous season is now defined. For each snow patch polygon in the 2010-2011 dataset, the percent of seasonal overlap is calculated by the ratio of area of intersection to the polygon area (Eq. 1):

$\%$ Seasonal overlap $=100 \cdot \frac{\mathrm{SCA}_{2009-2010} \cap \mathrm{SCA}_{2010-2011}}{\mathrm{SCA}_{2010-2011}}$.

The level of overlap was divided into four discrete categories: $0-25,25-50,50-75$, and $75-100 \%$ overlap (Table 1). For these counts, snow patches are considered to have a threshold of at least $50 \mathrm{~m}^{2}$ in area to be counted. The methods described here are applied to each $1 \mathrm{~km}^{2}$ plot and an example of this process shown in Fig. 4. The $1 \mathrm{~km}^{2}$ plots used to investigate snow dynamics at the snow-patch scale can also be used to test how the snow-patch scale reflects the landscape distribution of snow. During peak accumulation, Table 2 displays the total snow-covered area for each season and the ratio of 2010-2011 to 2009-2010 snow coverage for both the landscape scale and each $1 \mathrm{~km}^{2}$ plots. Peak accumulation during the 2010-2011 season is represented by the earliest available image (Fig. 2), which in most cases is after the 2009-2010 observed peak accumulation date of mid-October. The ratios of seasonal snow coverage (2009 peak accumulation to 2010 peak accumulation) for both scales, "landscape" and "plot ratios" in Table 2, are defined in Eqs. (2) and (3).

landscape ratio

$=\frac{\text { snow-covered area at landscape scale during } 2009 \text { peak accumulation }}{\text { snow-covered area at landscape scale during } 2010 \text { peak accumulation }}$

plot ratio

$=\frac{\text { snow-covered area within } 1 \mathrm{~km}^{2} \text { plots during } 2009 \text { peak accumulation }}{\text { snow-covered area within } 1 \mathrm{~km}^{2} \text { plots during } 2010 \text { peak accumulation }}$

For 15 snow patches ( 3 from each region) selected to be representative of the respective regions, frequent GPS measurements tracked the extent of area throughout the 2009-2010 ablation season. These measurements are of a very high spatial resolution on the order of only a few centimeters. These selected snow patches will be used to test how temporal trends of snow-covered area for individual snow patches reflect snow dynamics observed at the landscape scale.

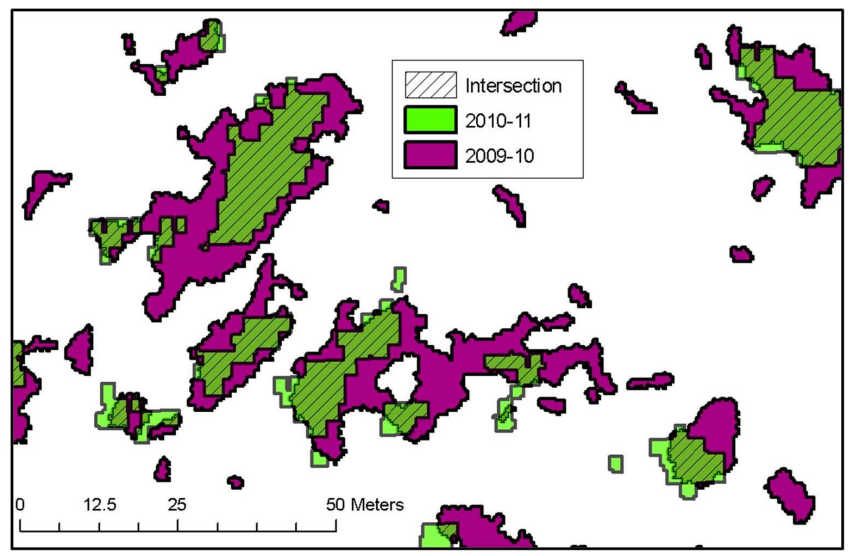

Fig. 4. Example of seasonal overlap methodology. This section of snow patches is taken from Plot 1 of the Fryxell region. Peak accumulation for this region for the two seasons is 30 October 2010 and 4 November 2011.

Table 1. Counts of snow patches in four categories of seasonal overlap by region.

\begin{tabular}{lcccc}
\hline \multicolumn{4}{c}{ Number of patches for given seasonal overlap } \\
\hline \multirow{4}{*}{ Region } & $0-25$ & $25-50$ & $50-75$ & $75-100$ \\
\cline { 2 - 5 } & 4 & 65 & 213 & 399 \\
Fryxell & 3 & 35 & 76 & 153 \\
Hoare & 0 & 0 & 0 & 10 \\
Bonney & 0 & 20 & 82 & 194 \\
Brownworth & 3 & 18 & 19 & 16 \\
Vanda & 3 & & & \\
\hline
\end{tabular}

\subsection{Landscape-scale analyses}

Additional analyses were undertaken to investigate controls on the seasonal distribution and ablation of snow. The percent of landscape covered by snow as a function of the distance along the dominant (W-E) orientation of Taylor Valley is determined by calculating the snow-covered area within several overlapping $2 \mathrm{~km}$ wide windows perpendicular to the along-valley axis length. Each of the 29 windows is centered at each $1 \mathrm{~km}$ interval from the eastern edge of the Fryxell region (Commonwealth Glacier) to the western edge of the Bonney region (Taylor Glacier). Calculating the percent of land covered by snow in each window yields a distribution representing "percent snow-covered" as a function of alongvalley distance measured at each kilometer. Note that only snow-covered area below the $500 \mathrm{~m}$ elevation contour is analyzed. We used the same basic approach to develop a similar relationship for snow-covered area as a function of elevation. The region of analysis is again considered to be between the Commonwealth Glacier and Taylor Glacier. Snow-covered area is calculated for each contour band representing a $50 \mathrm{~m}$ 


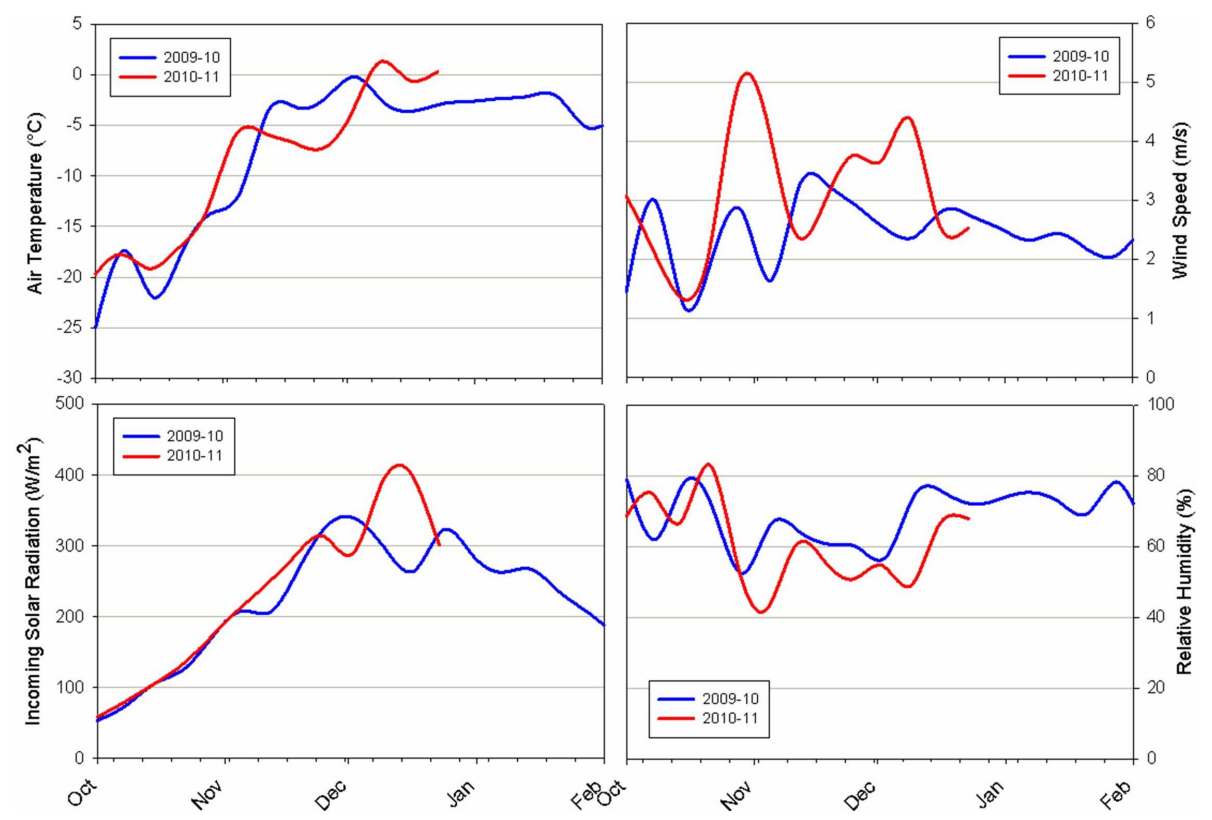

Fig. 5. Meteorological data for 2009-2010 and 2010-2011 seasons in the Hoare region. Each dataset consists of a running mean averaged over seven days.

increase in elevation between 0 and $500 \mathrm{~m}$; the percent of land covered by snow is calculated for each contour band.

To analyze ablation rates, data from the Hoare region were chosen for analysis because they have the best temporal resolution for the two seasons (Fig. 2). For both seasons, fitted curves for the time series of snow-covered area were plotted, and the derivative of these lines yielded ablation rates as a function of time. Available meteorological data were used to interpret these results. Measured air temperature, incoming shortwave radiation, wind speed, and relative humidity are available from the McMurdo Long Term Ecological Research (LTER) network (http://www.mcmlter.org/queries/ met/met_home.jsp). The meteorological data measured at the southern shore of Lake Hoare are shown in Fig. 5, which for the purposes of the ensuing discussions will be representative of the climate in Taylor and Wright valleys. There is general agreement among these variables for both seasons. The exception is wind speed, which is highly variable interannually. Peaks of high wind speeds correspond to drainage wind events (Nylen et al., 2004; Speirs et al., 2010).

Snow patches in the Dry Valleys have the potential to influence subnivian communities in two ways: by providing protection form temperature extremes and by providing a source of moisture. Assessing the spatial and temporal dynamics of snow-covered area is important to determine the potential of snow patches to provide protection from temperature extremes. However, to determine the potential of snow patches to provide moisture, snow water equivalent should be investigated. To model ablation on snow water equivalent throughout the summer seasons of 2009-2010 and 2010-2011, the Utah Energy Balance Snow Accumulation and Melt Model
(UEB) (Tarboton and Luce, 1996) was employed for 5 hypothetical snow patches with characteristics representative of the 5 regions. Meteorological inputs are unique for each regional analysis, while parameters with regard to snow properties are the same for each region. While this analysis only provides a rudimentary view of the dynamics associated with snow water equivalent, it is important to investigate the relationship between snow-covered area and snow water equivalent due the heavy reliance on extracted snow-covered area for this study.

Data from nearby meteorological stations were available for model inputs. Depths of snow patches are variable within each individual patch, but most patches do not exceed depths of $0.5 \mathrm{~m}$. A depth of $0.25 \mathrm{~m}$, which is typical of snow patches observed in the field, is used as the initial depth. The analysis starts on the apparent date of peak accumulation, October 15, which was determined from the previous landscape analysis of snow-covered area (Eveland et al., 2013). Initial energy content is calculated as a function of mean snow temperature and snow density. To initialize the model, mean snow temperature during peak accumulation is assumed to be equal to air temperature, and a value of $350 \mathrm{~kg} \mathrm{~m}^{-3}$ is used for snow density based on field measurements. Other inputs and model parameters used during the model runs are set to default values (Tarboton and Luce, 1996). 

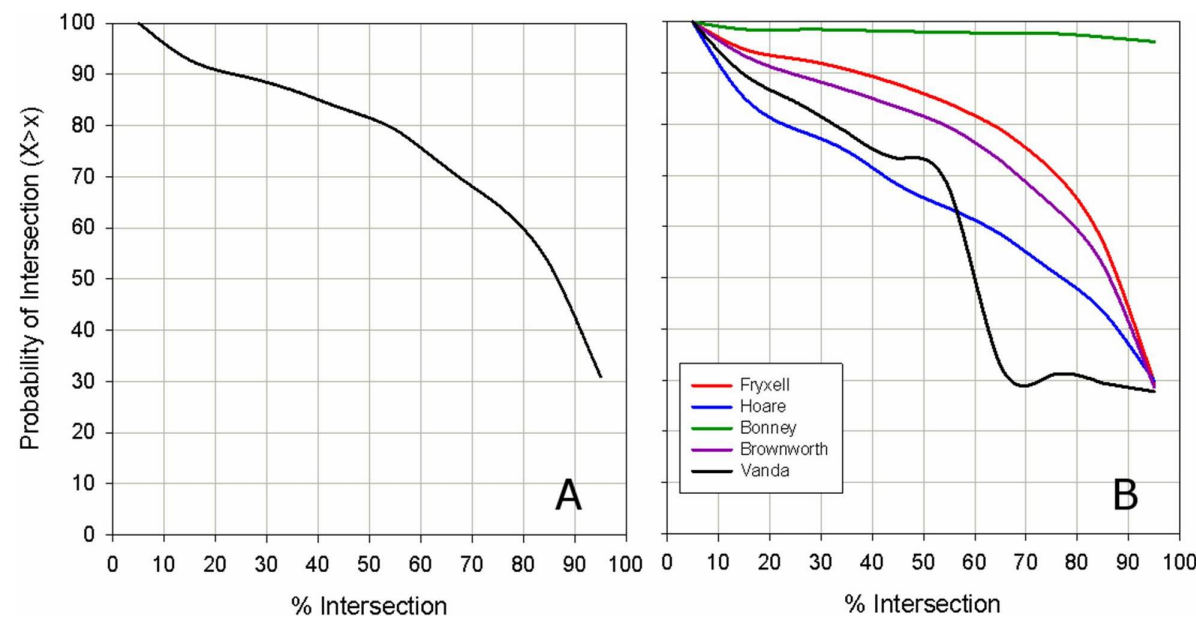

Fig. 6. Exceedance probabilities for defined levels of intersection for total snow patches of every $1 \mathrm{~km}^{2}$ plot $(\mathbf{A})$ and by regions $(\mathbf{B})$. For the Fryxell, Hoare, Bonney, Brownworth, and Vanda regions, 681, 267, 10, 296, and 56 snow patches were analyzed respectively.

Table 2. Seasonal differences in snow-covered area for landscape and $1 \mathrm{~km}^{2}$ plots.

\begin{tabular}{llrrrrrrr}
\hline Region & Plot & $\begin{array}{r}\text { Landscape SCA } \\
2009\left(\mathrm{~km}^{2}\right)\end{array}$ & $\begin{array}{r}\text { Landscape SCA } \\
2010\left(\mathrm{~km}^{2}\right)\end{array}$ & $\begin{array}{r}\text { Landscape ratio } \\
(2009 / 2010)\end{array}$ & $\begin{array}{r}\text { Plot SCA } \\
2009\left(\mathrm{~km}^{2}\right)\end{array}$ & $\begin{array}{r}\text { Plot SCA } \\
2010\left(\mathrm{~km}^{2}\right)\end{array}$ & $\begin{array}{r}\text { Plot ratio } \\
(2009 / 2010)\end{array}$ & $\begin{array}{r}\text { Scale difference } \\
(\text { landscape }- \text { plot })\end{array}$ \\
\hline Fryxell & 1 & 10.290 & 7.555 & 1.36 & 0.074 & 0.041 & 1.82 & -0.462 \\
Fryxell & 2 & 10.290 & 7.555 & 1.36 & 0.433 & 0.292 & 1.48 & -0.120 \\
Fryxell & 3 & 10.290 & 7.555 & 1.36 & 0.230 & 0.174 & 0.040 \\
\hline Hoare & 1 & 1.850 & 0.807 & 2.29 & 0.164 & 0.053 & 3.09 & -0.792 \\
Hoare & 2 & 1.850 & 0.807 & 2.29 & 0.090 & 0.038 & 2.39 & -0.101 \\
Hoare & 3 & 1.850 & 0.807 & 2.29 & 0.102 & 0.042 & 2.43 & -0.139 \\
\hline Bonney & 1 & 1.110 & 0.031 & 35.78 & 0.062 & 0.000 & 253.19 & -217.413 \\
Bonney & 2 & 1.110 & 0.031 & 35.78 & 0.157 & 0.022 & 7.01 & 28.763 \\
Bonney & 3 & 1.110 & 0.031 & 35.78 & 0.034 & 0.001 & 55.26 \\
\hline Brownworth & 1 & 2.557 & 0.559 & 4.57 & 0.204 & 0.063 & 3.22 & -19.483 \\
Brownworth & 2 & 2.557 & 0.559 & 4.57 & 0.287 & 0.057 & 5.07 \\
Brownworth & 3 & 2.557 & 0.559 & 4.57 & 0.216 & 0.034 & 6.39 \\
\hline Vanda & 1 & 0.260 & 0.096 & 2.70 & 0.022 & 0.002 & 1.351 \\
Vanda & 2 & 0.260 & 0.096 & 2.70 & 0.017 & 0.002 & -0.498 \\
Vanda & 3 & 0.260 & 0.096 & 2.70 & 0.087 & 0.066 & -1.820 \\
\hline
\end{tabular}

\section{Results}

\subsection{Seasonal comparison of accumulation and aerial ablation patterns}

\subsubsection{Snow-patch scale}

The results of the fine-scale analysis confirm the generally held belief that snow patches will form in the same locations each season. However, as previously mentioned, there is a degree of uncertainty in the results due to issues involving image alignment. These errors likely skew the results towards snow patches having less overlap. Therefore, it is likely that these results represent a minimum degree of seasonal overlap, and the actual degree of seasonal overlap is somewhat greater. Nevertheless, the results provide key insights into snow-patch dynamics at fine scales. Except for the Vanda region, most snow patches fall into the category of $75-100 \%$ seasonal overlap (Table 1). However, this is misleading because most of these snow patches in the Vanda region are at high elevations near alpine glaciers (see Vanda plot 3 in Fig. 3) and do not reflect the seasonal overlap exhibited in the other Vanda region plots.

The probability of seasonal overlap, measured by the proportion of snow-covered area corresponding to a given level of intersection to the total snow-covered area within the plots, is shown in Fig. 6 for all plots combined (Fig. 6a) and for each region (Fig. 6b). It is important to note here that the seasonal overlap does not represent snow patches persisting from the 2009-2010 to the 2010-2011 season without 


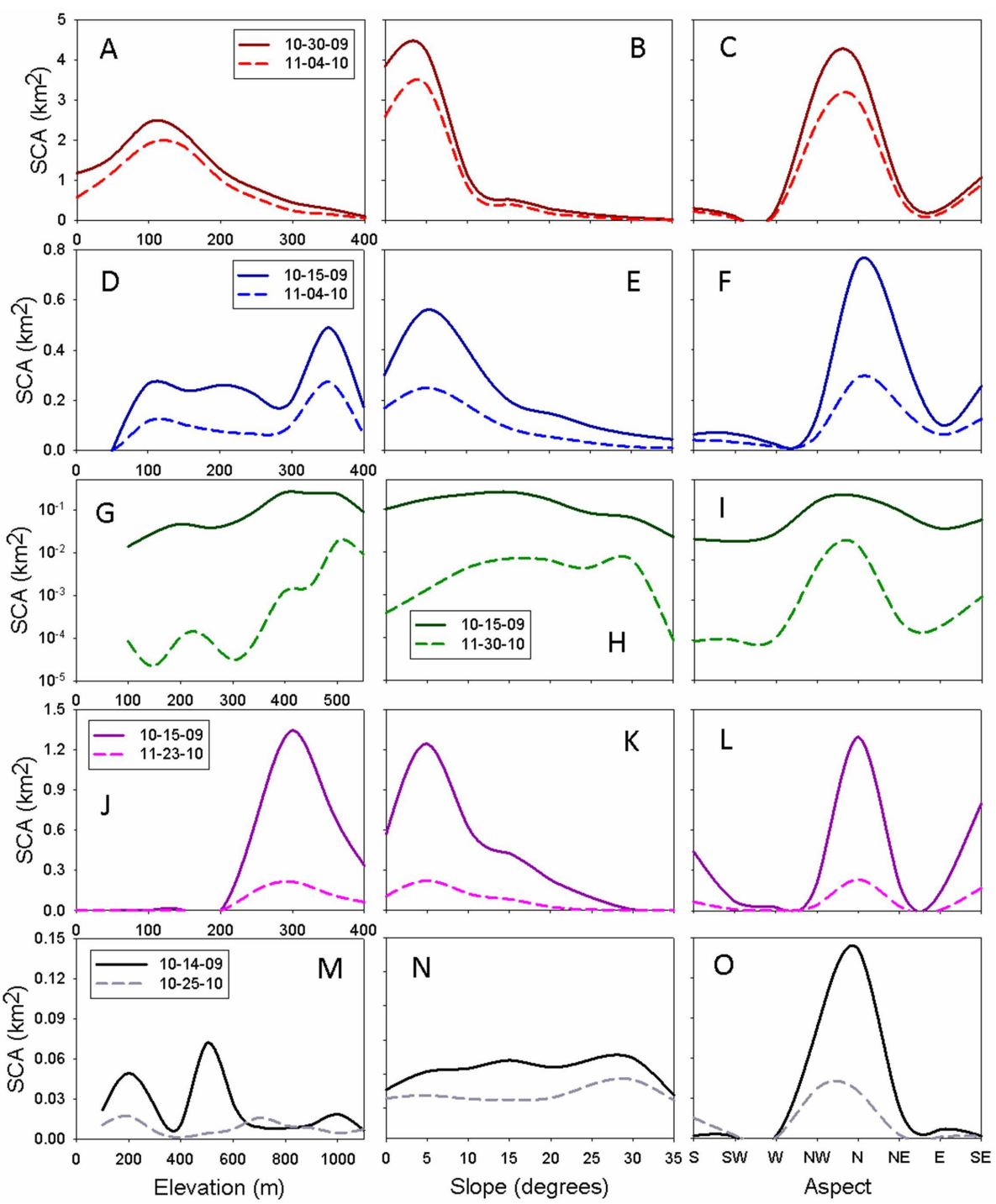

Fig. 7. Peak accumulation distributions of snow-covered area with respect to topography for Fryxell (row 1), Hoare (row 2), Bonney (row 3 ), Brownworth (row 4), and Vanda (row 5) regions.

ablation. These data along with Eveland et al. (2013) indicate that patches that seasonally overlap will accumulate in the austral winter, ablate during the austral spring and summer, and then re-accumulate in the same locations over the following winter. Notably, the Bonney region exhibits almost complete seasonal overlap. This may be misleading, because the 2009-2010 snow-covered area is used as a baseline. Almost all of the very few snow patches of the 2010-2011 season are contained within the 2009-2010 snow patches for the Bonney region. However, the majority of the 2009-2010 snow patches do not appear in the 2010-2011 images, presumably because they had already ablated by the time the first images were available. The Vanda region displays a unique trend because snow-covered area here is limited to several pockets rather than distributed across the entire landscape. Other regions display trends similar to each other with regions with the highest degree of snow cover (Fryxell and Brownworth) exhibiting greater seasonal overlap.

\subsubsection{Landscape scale}

The distributions of snow-covered area (SCA) with respect to elevation, slope, and aspect near peak accumulation for both seasons are shown for each region in Fig. 7. The "near peak accumulation" caveat is due to the lack of available imagery of sufficient quality during peak accumulation for some regions (Fig. 2). Previous work has shown the peak accumulation of seasonal snow to occur around mid-October for Taylor and Wright valleys (Eveland et al., 2013). For most regions (Fryxell, Hoare, and Brownworth), the seasonal distributions completely correspond to each other but with lower magnitudes during the 2010-2011 season. The modes of the 
distribution with respect to elevation, slope, and aspect exhibit a much less snow-covered area for the 2010-2011 season, which is similar to the manner in which distributions of snow-covered area evolve throughout a single season (Eveland et al., 2013). This indicates that aerial ablation had already begun before the first available image in 2010-2011. For those sites with particularly high ablation rates (Bonney and Vanda), the seasonal distributions differ slightly. Because ablation occurs rapidly here, snow-covered areas from images a few weeks after peak accumulation are probably not representative of the true peak accumulation distribution. Note that the distributions in the Bonney region are displayed on a log scale to better visualize the limited snow-covered area in this region.

The previously defined ratios of seasonal snow coverage for both scales, "landscape" and "plot ratios" defined in Eqs. (2-3) and displayed in Table 2, are greater than unity. This is due to the overall lower magnitude of snow-covered area during the 2010-2011 season, presumably due to either lower accumulation at the onset of the season or because of high aerial ablation rates before the first available image in early November. Notably, the landscape ratio for coastal sites is much lower than those inland sites experiencing greater ablation rates. This is expected because imagery was not available during the 2010-2011 peak accumulation, and ablation had already begun to accelerate.

The difference between these ratios (last column of Table 2) is substantial for some of the plots. If the $1 \mathrm{~km}^{2} \mathrm{di}-$ rectly reflected the landscape scale, the difference between scales would be close to zero. In coastal regions (Fryxell, Hoare, and Brownworth) with more ubiquitous snow coverage, the "scale difference" (difference between landscape ratio and plot ratio) is closer to zero, but the inland regions (Bonney and Vanda) exhibit considerable differences between the two scales. Because the inland regions experience greater ablation rates, spatial patterns of snow distribution will quickly deviate from the peak accumulation patterns of snow-covered area. This leads to distributions of snow in high ablation regions to be limited to pockets of a few deeper and more persistent snow patches, compared to the coastal sites. In Fig. 8, a histogram displays the "scale difference" (Table 2) for all 15 plots with the exception of Bonney plot 1 , which was considered to be an outlier. With a mean very close to zero $(\mu=-0.55)$, it can be inferred from this comparison of scales that given a large enough sample size of fine-scale plots, on average the fine-scale plots reflect the landscape scale. However, the large variance of the distribution should be noted, highlighting how certain fine-scale plots and individual snow patches can greatly deviate from the mean response of the landscape scale.

Temporal changes in snow-covered area for select snow patches reflect observations at the landscape scale. Figure 9 displays the temporal changes in area for snow patches selected in the field, prior to the image-based analysis, to be representative of the respective regions. Additionally, the

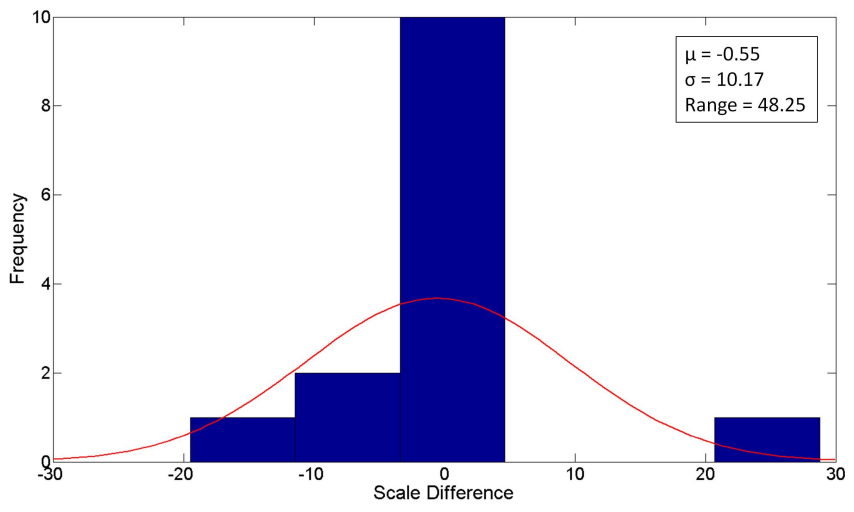

Fig. 8. Histogram of "scale difference" for $1 \mathrm{~km}^{2}$ plots. Bonney plot 1 is excluded because it is a strong outlier.

time series of snow-covered area at the landscape scale is shown. The data displayed are from the 2009-2010 season, with the Vanda region excluded because rapid ablation allowed for only one GPS survey of snow patches at the site. It is necessary to note the temporal resolution of each dataset, considering the differences in the timing of the GPS measurements for representative snow patches and the availability of images for the landscape time series. In general, the slopes corresponding to aerial ablation rates appear to change similarly at both scales. Notably, the rates of aerial ablation appear to taper near the end of the season. This trend is reflected at both scales.

\subsection{Seasonal controls on snow accumulation and aerial ablation}

The distance across the dominant (E-W) orientation of Taylor Valley, or distance from the Ross Sea, influences the distribution and ablation of seasonal snow. Figure 10 shows the percent of landscape covered by snow for early and late season times (below $500 \mathrm{~m}$ elevation) during the 2009-2010 and 2010-2011 seasons; the $\mathrm{x}$-axis is reversed and the alongvalley distance of zero corresponds to the eastern edge of the Fryxell region. The early season distribution for the 2009-2010 season is during late October, and the late season distribution is during mid-January. The early season distribution for the 2010-2011 season is a composite of early and late November snow-covered area, depending on the spatial coverage of the respective images. The late season distribution is a composite of extracted snow-covered area from several mid-December composites. There is clearly a strong gradient of snow-covered area decreasing with along-valley distance (distance from the sea). During the peak accumulation in the 2009-2010 season, nearly $25 \%$ of the eastern-most portion of the analysis range is snow-covered, while less than $5 \%$ of the western-most portion is snow-covered. This gradient occurs over a range of less than $30 \mathrm{~km}$. While there is significantly less snow-covered area in the 2010-2011 season, the 


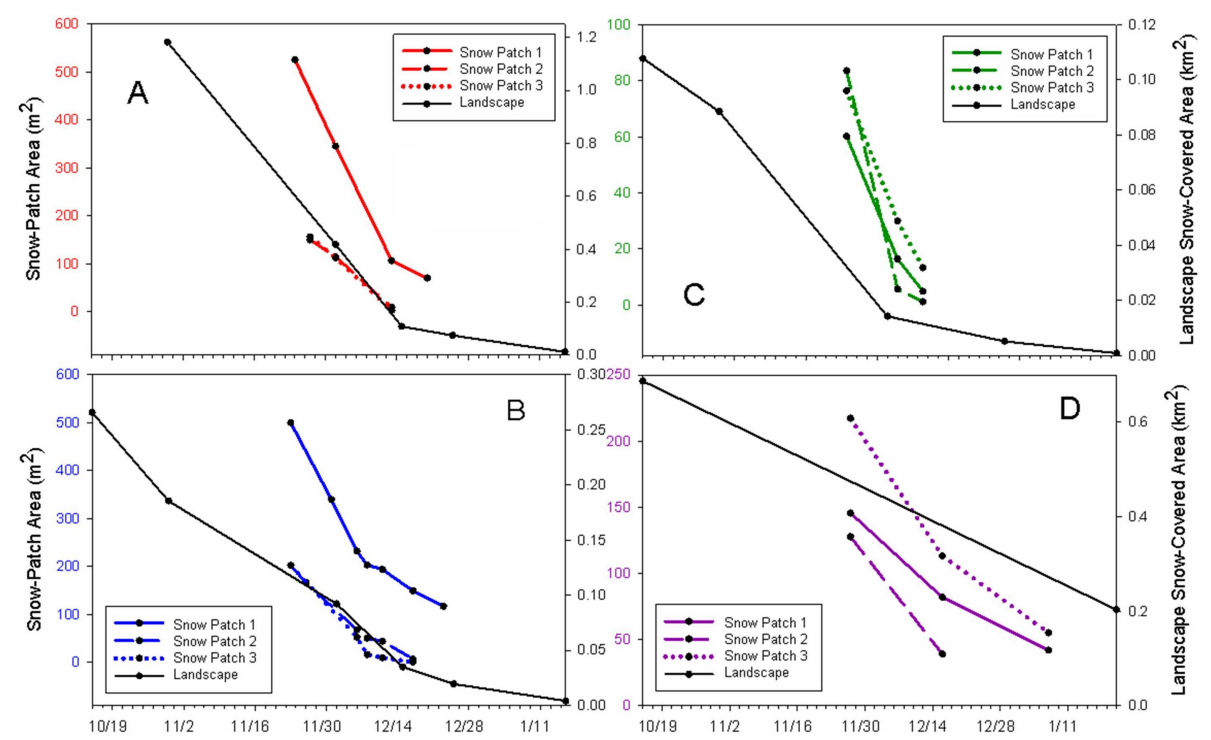

Fig. 9. Time series of snow-covered area for GPS-monitored snow patches and landscape scale for the (A) Fryxell, (B) Hoare, (C) Bonney, and (D) Brownworth regions during the 2009-2010 season.
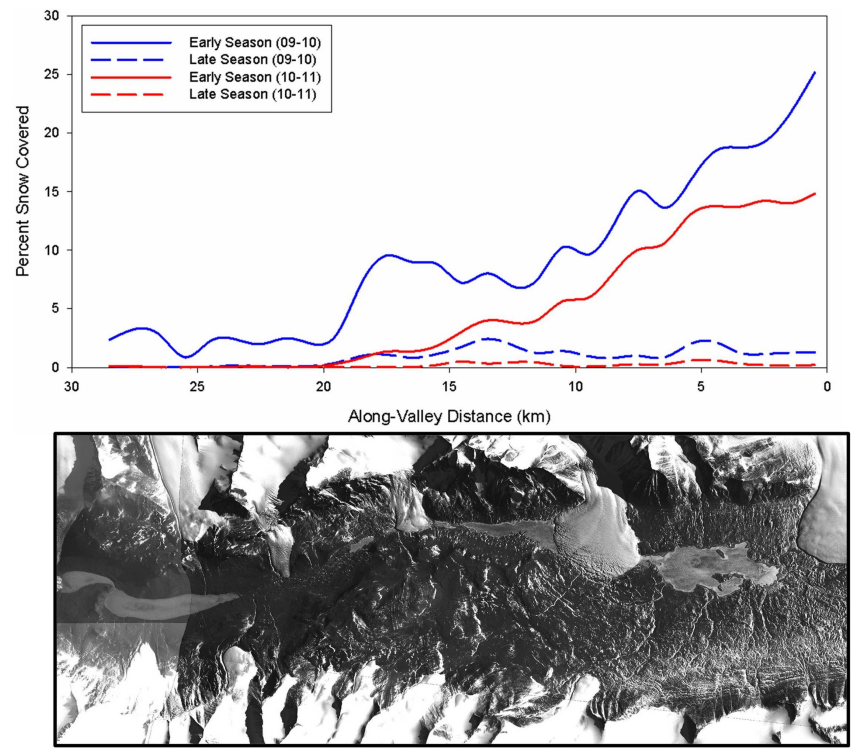

Fig. 10. Seasonal early and late season distributions of snowcovered area as functions of along-valley distance shown with a late October, 2009, image corresponding to the above along-valley distance. The valley shown is Taylor Valley.

gradient of snow-covered area as a function of along-valley distance is nearly identical. For both seasons, the gradient of snow-covered area with along-valley distance becomes much less pronounced near the end of the ablation season.

Elevation acts as an additional control over the seasonal distribution and ablation of snow in the valleys (Fig. 11). Similar to the manner in which the distributions in Fig. 10 were constructed, Fig. 11 shows the percent of landscape covered by snow as a function of elevation. To visualize the effects of aerial ablation on the distributions of snowcovered area with respect to elevation, the data in Fig. 11 are displayed using a log scale for the y-axis. These distributions pertain to the greater region of Taylor Valley between the Taylor and Commonwealth glaciers for elevations up to $500 \mathrm{~m}$. Because the valley bottom elevation increases with distance from the coast by approximately $100 \mathrm{~m}$, the effects of along-valley distance are also evident in the distributions with respect to elevation. The percent of landscape covered by snow clearly peaks at approximately $125 \mathrm{~m}$, but at the end of the ablation season there are bimodal peaks at $125 \mathrm{~m}$ and $475 \mathrm{~m}$. During peak accumulation in the 2009-2010 season, a second smaller peak occurs at $425 \mathrm{~m}$, which is due to the addition of snow-covered area in the Bonney region. For the 2010-2011 season, an early image was not available for this region, so much of the snow-covered area had likely ablated by late November. As the ablation season progresses, a sharp decrease in percent snow covered occurs at low elevations, while only a modest decrease in percent snow covered is evident at higher elevations. A sharp decrease also appears at $275 \mathrm{~m}$, which is similar to a decrease observed in the Fryxell region (Fig. 12).

Plotted on log scale to highlight subtle changes, Fig. 12 shows the seasonal distributions of snow-covered area with respect to elevation for the Fryxell region. Compiling the distribution for every available time, including both seasons, reveals a consistent evolution of distributed snow-covered area as the overall magnitude of snow-covered area in the region decreases. The Fryxell region was chosen to highlight the evolution of seasonal distributions because it has the most ubiquitous patterns of snow accumulation over a broad area in addition to sufficient availability of imagery. After peak 


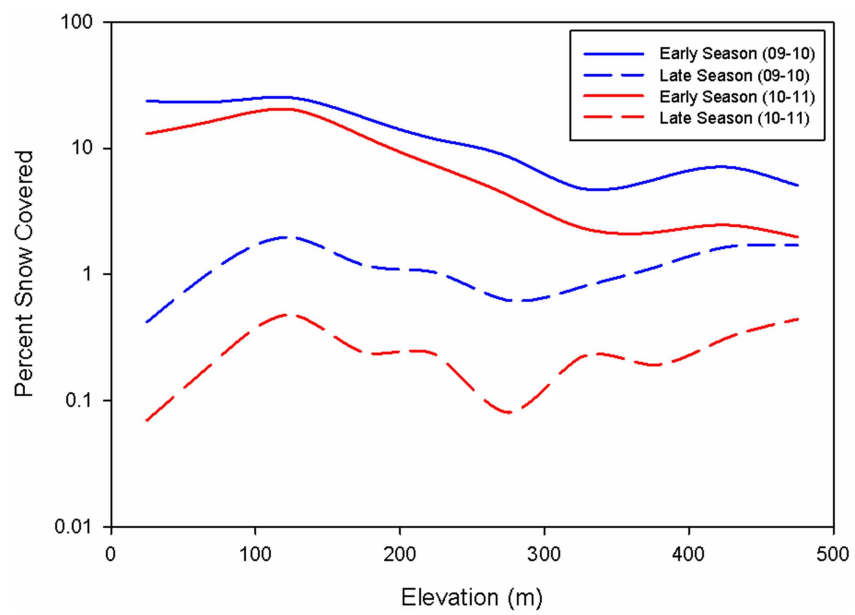

Fig. 11. Seasonal early and late season distributions of snowcovered area in Taylor Valley as functions of elevation. Despite the differences in magnitudes, the patterns are similar.

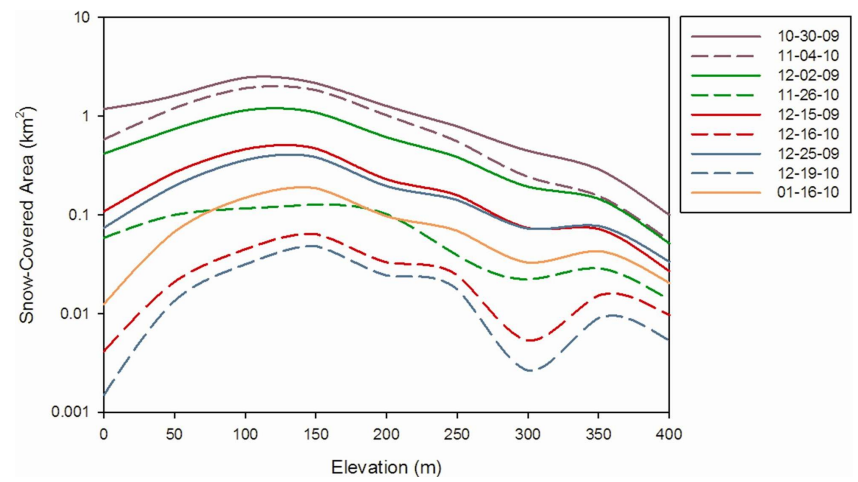

Fig. 12. Seasonal distributions of snow-covered area with respect to elevation in the Fryxell region.

accumulation, ablation begins to change the shape of the distribution in a predictable manner regardless of the season. For example, it would be reasonable to expect the shape of the late season distribution in the 2009-2010 season (16 January 2010) to evolve into distributions similar in shape to those observed at the end of the 2010-2011 season (16 December 2010 and 19 December 2010) if observations continued past mid-January in the first season. This suggests that while the magnitude and timing of aerial ablation may differ seasonally, the shapes of distributions of snow-covered area will evolve similarly. The only exception to the apparent pattern of aerial ablation is the snow-covered area observed from 0 to $75 \mathrm{~m}$ on 26 November 2010 . Snow-covered area at $300 \mathrm{~m}$ elevation noticeably decreases at a faster rate in both seasons, relative to the 250 and $350 \mathrm{~m}$ elevation contours.

\subsection{Snow ablation rates and modeled snow water equivalent}

The timing and magnitude of aerial ablation is seasonally variable, and drainage winds observed in the meteorological data appear to act as a primary control (Fig. 5). Aerial ablation rates throughout both seasons, shown in Fig. 13b, are the derivatives of the time series of snow-covered area at the landscape scale shown in Fig. 13a. The peaks in aerial ablation rates for the 2010-2011 season directly correspond to the times of high wind speed events observed in the meteorological data. Additionally, the magnitude of incoming solar radiation peaks and air temperature reaches near or above freezing during early December, for which increases in aerial ablation rates are observed in both seasons. Because the 2009-2010 ablation season was milder with respect to wind speed and air temperature, the interpretation of aerial ablation rates is less obvious and cannot be contributed to strong individual events. Aerial ablation occurred very early during the 2010-2011 season evident by the low magnitude of snow cover observed in the first available image (4 November 2010) and the high initial rate observed in Fig. 13b. However, the greatest aerial ablation rates occurred during early December for the 2010-2011 season. Despite less favorable conditions for ablation (lower air temperature, reduced solar radiation, lower wind speeds, and higher relative humidity) in early December of 2009 relative to the same time in 2010, much higher aerial ablation rates are observed. The aerial ablation rate for the 2010-2011 season during this time would likely surpass the peak during the 2009-2010 season if much of the snow had not already ablated. In 2010, the remaining snow-covered area at this point would be confined to deeper snow patches, which maintain their area of extent longer.

Modeling of snow water equivalent supports the landscape observations of snow-covered area. Figure 14 shows the results of the UEB model run for the five hypothetical snow patches using input data from both seasons. Typically, snow patches do not exceed $0.5 \mathrm{~m}$ in depth, so the use of $0.25 \mathrm{~m}$ as an initial depth is appropriate given that most snow patches observed in the field are of this depth. Because all hypothetical snow patches have the same initial depths at the time of peak accumulation, regional analyses can be undertaken without the confounding effects of depth. For some regions, the model results do not reflect the observed aerial ablation rates with modeled snow water equivalent lasting well past observed ablation. This may indicate processes controlling ablation that are not well accounted for in the model, possibly pronounced changes in the energy balance as the snow patches become very shallow. Observed completed ablations for monitored snow patches in the Bonney and Vanda regions correspond to the modeled completed ablation times of mid-December and late November respectively. However, snow water equivalent in the Fryxell, Hoare, and Brownworth regions persists much 


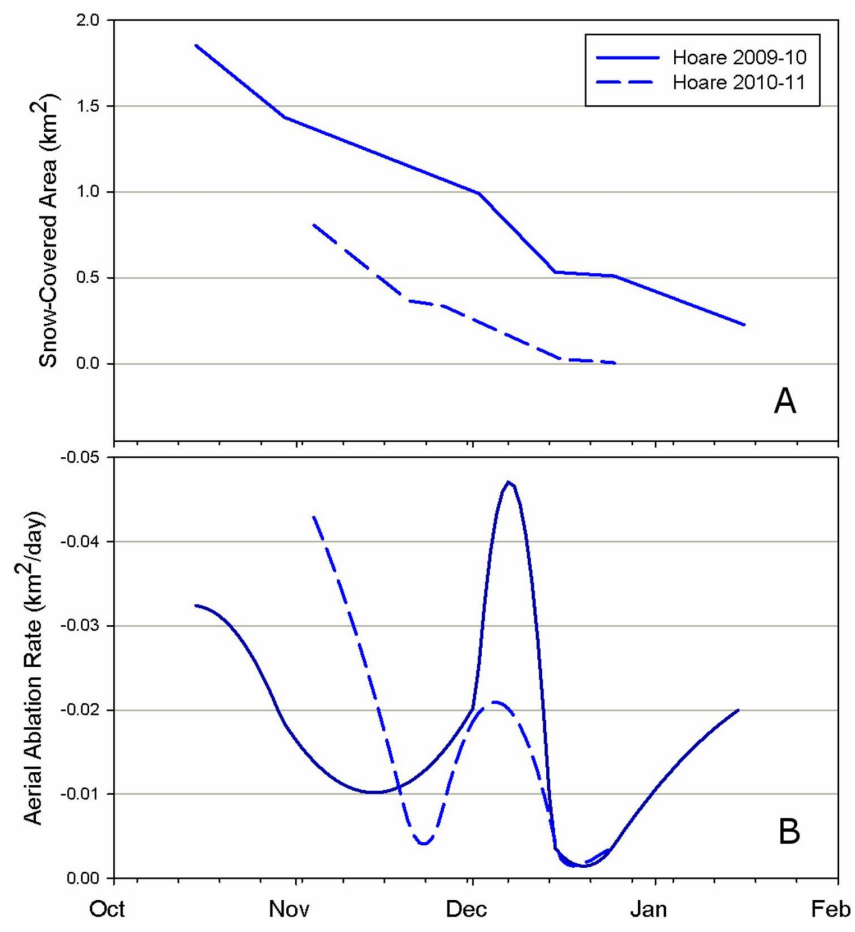

Fig. 13. Time series of snow-covered area in the Hoare region with corresponding aerial ablation rates.

longer than observed completed ablation in the field. Monitored snow patches in the Fryxell and Hoare regions completed ablation around late December, while 2 of the 3 monitored snow patches persisted in the Brownworth region during the last field visit in early January. The relative ablation rates for these regions seem consistent with aerial ablation observations (Fryxell $\simeq$ Hoare $>$ Brownworth), but observations of aerial ablation suggest completed ablation should occur earlier. Consistent with aerial ablation observed from the high-resolution imagery, modeled snow water equivalent in the 2010-2011 season decreases much more rapidly than the 2009-2010 season.

\section{Discussion}

\subsection{Influence of scale on accumulation and aerial ablation patterns}

Snow dynamics in the McMurdo Dry Valleys are influenced by processes that occur at both the snow-patch and landscape scales. Snow generally accumulates in a predictable manner, primarily controlled by topography, but considerable variation exists at the snow-patch scale. For example, at the plot scale $\left(1 \mathrm{~km}^{2}\right)$, a sizeable number of snow patches in the Fryxell region fall outside the $75-100 \%$ seasonal overlap category. However, these effects are dampened at the landscape scale. While imagery captures snow-covered area at $0.5 \mathrm{~m}$ resolution, the analysis conducted at the landscape scale inte-

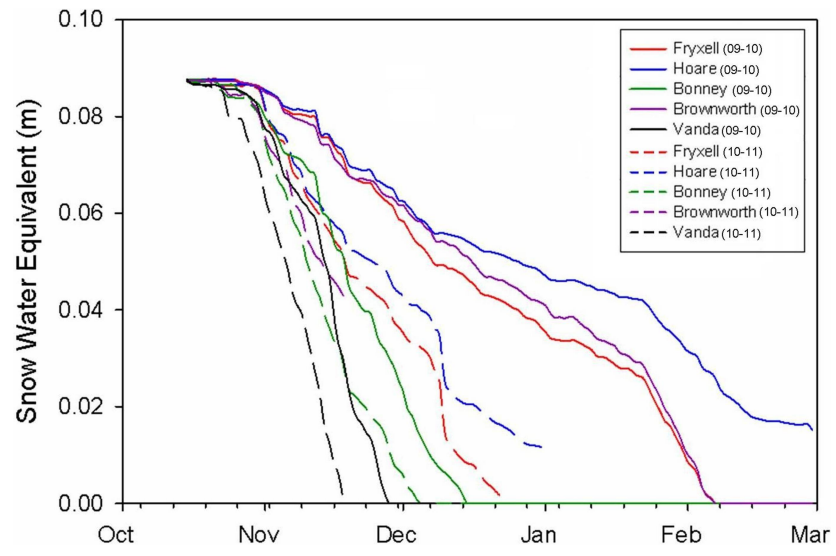

Fig. 14. Seasonal comparison of modeled snow water equivalent for each region using an initial depth of $0.25 \mathrm{~m}$. Solid lines represent the 2009-2010 season, and dashed lines represent the 2010-2011 season.

grates variations in aerial ablation of individual snow patches by lumping together all snow patches that fall within topographic bins.

While individual snow patches respond to changes in meteorological conditions just as the snow-covered area at the landscape does (Fig. 9), some snow patches appear to be more sensitive to increases in energy fluxes than the mean response observed at the landscape scale, which is an integration of all individual snow patches. Snow patch depths are not represented in Fig. 9, but shallow snow patches have been observed to ablate faster in the field. The representative snow patches within the respective regions of analysis are in close proximity to each other and are generally separated by only a few hundred meters or less. Given the same general topography (i.e., elevation, aspect, and slope) and meteorological conditions, aerial ablation would be expected to be very similar without considering local effects on individual snow patches. However, while the monitored snow patches in some regions exhibit minor variation, there is considerable variation among neighboring snow patches in other regions.

This can be explained by local effects, produced by the microtopography of areas to which individual snow patches or collections of adjacent snow patches are confined. In this context, microtopography refers to the topography at the scale of approximately $1-100 \mathrm{~m}$. At this scale, deviations from the aggregated landscape scale are observed. Microtopography may influence snow ablation processes by several means.

The underlying topography beneath individual snow patches produces varying sizes and depths of snow patches. For shallow snow patches, the effective albedo is reduced due to complete penetration of solar radiation to the ground surface. This alters the energy balance of shallow snow patches, making them more susceptible to ablation. This may explain why neighboring snow patches, which can have significant 
differences in depth, can exhibit substantially different ablation rates. Additionally, it appears that the complex terrain of the Dry Valleys may be a significant control over wind flow at fine scales. For example, the topography immediately surrounding snow patches may reduce energy fluxes into snow patches by protecting them from strong winds. Large boulders have been observed to protect down-wind snow patches of a few meters in length well into the ablation season. This may explain why particular snow patches, possibly deeper and protected from additional energy fluxes, do not ablate until the end of the warm season. Because of rough terrain caused by glacial action, these types of effect should not be expected to be negligible. It should be noted that the DEM used throughout this investigation does not have sufficient resolution to resolve these fine-scale microtopographic effects.

\subsection{Seasonal controls on snow accumulation and serial ablation}

Proximity to coastal zones is clearly an important control on the accumulation and aerial ablation of seasonal snow at the landscape scale (Fig. 10). Snow-covered area near the coast in eastern Taylor Valley may represent as much as $25 \%$ of the landscape, while snow-covered area at the most inland region represents less than $5 \%$ of the landscape (Fig. 10). At the end of the ablation season, snow-covered area at the inland region of Taylor Valley is almost non-existent. While differing in magnitude, the seasonal distributions of snow-covered area with respect to along-valley distance appear to be similar. The meteorological gradients in Taylor Valley, as well as Wright Valley, are such that temperature and wind speed increase with distance from the coast. Relative humidity decreases with increasing distance from the coast (Doran et al., 2002). High temperatures and wind speeds with low relative humidity provide more favorable conditions for ablation, explaining the strong gradient observed in Taylor Valley. During peak accumulation, the distribution of snow-covered area is fairly ubiquitous with respect to elevation, but differences in elevation produce preferential patterns of aerial ablation as the season progresses (Fig. 11). At the end of the ablation season, there is a large reduction in snow-covered area for regions of elevation less than $100 \mathrm{~m}$. Considering the adiabatic lapse rate, air temperatures are much warmer at lower elevations (Doran et al., 2002). Additionally, higher wind speeds, produced from drainage winds from the Polar Plateau (Nylen et al., 2004), contribute to a higher potential for ablation near the valley bottoms.

Figure 12 provides insights into the controls on spatial patterns of aerial ablation. Despite differences in the overall magnitude of snow-covered area for both observed ablation seasons, the distribution of snow-covered area appears to evolve in a similar manner both seasons. Meteorological gradients that produce conditions favorable for ablation at particular locations should remain constant. This leads to the conclusion that in each season particular locations are more susceptible to ablation of seasonal snow cover, while other locations are more inclined to maintain more persistent snow cover. However, because the magnitude of accumulated snow at the onset of the ablation season is highly variable, magnitudes of ablation can differ substantially for a given season.

\subsection{Snow ablation rates and modeled snow water equivalent}

The remote-sensing-based analyses of two recent seasons in conjunction with past studies of snowfall measurements have shown the magnitude of seasonal snow dynamics to vary greatly (Keys, 1980; Bromley, 1985; Fountain et al., 2009). The magnitude of accumulated snow at the onset of the ablation season determines the amount of snow available for ablation and thus controls the amount of potential moisture available for subnivian communities. Additionally, temporal dynamics in weather within individual seasons is important to consider. Differences in the timing and rates of ablation for each season highlight the temporal variability within a single season as shown in Fig. 13. During seasons of less accumulation, snow can be completely ablated early in the season due to a spike in ablation caused by a strong wind event or otherwise significant increase in energy input to the snow. Under this scenario, the potentially beneficial effects of snow on the underlying soil are lost well before the end of the summer. Seasons with greater snow accumulation can better buffer peak ablation rates caused by strong wind events.

The modeling of snow water equivalent for hypothetical snow patches of varying depths supports the observations of snow-covered area in the image-based analysis. Confirming that snow-covered area can be used as a proxy for measuring ablation at sufficiently large scales is necessary given the motivation of snow to act as a potential moisture source. While the area of snow patches provides protective cover for subnivian communities, it is the loss of snow water equivalent that can potentially provide moisture to the soil in the form of melt. For individual snow patches, the relationship between the mass of ablated snow and its reduction in area may vary greatly, but analysis at the landscape scale integrates these effects of individual snow patches. Because the regional trends observed in modeled snow water equivalent throughout the ablation season reflect that observed in the temporal trends of snow-covered area, it is appropriate to consider the loss of snow-covered area to be proportional to the mass of ablated snow at the landscape scale.

\section{Conclusions}

Analyzing the seasonal differences of snow distribution and aerial ablation has provided insights into the manner in which accumulation and ablation occur. Investigating these dynamics at both the snow-patch and landscape scales has 
shown that individual snow patches may deviate significantly from spatial and temporal patterns observed at the landscape scale. An important conclusion is the confirmation that snow patches will generally accumulate in the same locations each year. While previous studies have drawn similar conclusions for more conventional study regions, this is something that has not been previously confirmed in the Dry Valleys, which has a unique climate and snow distribution mechanisms. This is integral to understanding spatial processes associated with biogeochemical cycling and the structuring of microbial communities. The significance of snow patches to subnivian communities is predicated upon snow patches providing consistent protection from year to year.

At the landscape scale, the shapes of seasonal distributions of snow-covered area with respect to topography during peak accumulation are almost identical for most regions. Finescale analysis has shown that individual snow patches can deviate greatly from the integrated spatial patterns observed at the landscape scale. This implies there are additional local effects controlling aerial ablation other than regional topography and valley position (i.e., distance from the coast). This includes the compounding effects due to variable snow depths and the fine-scale topography surrounding individual snow patches.

The seasonal analysis, while limited to only two seasons, has shown spatial patterns of snow distribution and aerial ablation to be generally consistent, but the magnitude and timing of ablation can vary greatly. Along-valley distance, which produces meteorological gradients, appears to be a strong control on the seasonal distribution and aerial ablation of snow. Additionally, elevation is a strong control on aerial ablation in both seasons. The distributions of snowcovered area appear to evolve as ablation occurs in a predictable manner that is a function of the overall magnitude of snow-covered area, independent of season. The rate of ablation is controlled by the intensity of favorable meteorological conditions within individual seasons. Investigating aerial ablation rates has shown that ablation can occur rapidly through individual strong wind events. Because the frequency and timing of drainage winds are highly variable, ablation rates can vary greatly inter-annually and within individual seasons. Additionally, the modeling of snow water equivalent for hypothetical snow patches of varying depths supports and supplements the use of snow-covered area as a basis for studying ablation.

Acknowledgements. This project is funded through the National Science Foundation's Office of Polar Programs. This material is based upon work supported by the National Science Foundation under Grant Nos. 0830050, 0838879, and 0838922. The authors also recognize support by Raytheon Polar Services, Petroleum Helicopters, and the McMurdo Long Term Ecological Research project. Any opinions, findings, and conclusions or recommendations expressed in this material are those of the authors and do not necessarily reflect the views of the National Science Foundation.
Orthorectified images were acquired from the Polar Geospatial Center (http://pgc.umn.edu/), which is funded under National Science Foundation award ANT-1043681.

Edited by: M. Schneebeli

\section{References}

Ayres, E., Nkem, J. N., Wall, D. H., Adams, B. J., Barrett, J. E., Simmons, B. L., Virginia, R. A., and Fountain, A. G.: Experimentally increased snow accumulation alters soil moisture and animal community structure in a polar desert, Polar Biol., 33, 897-907, 2010.

Barrett, J. E., Virginia, R. A., Wall, D. H., Doran, P. T., Fountain, A. G., Welch, K. A., and Lyons, W. B.: Persistent effects of a discrete climate event on a polar desert ecosystem, Glob. Change Biol., 14, 2249-2261, 2008.

Bertler, N. A. N., Mayewski, P. A., Barrett, P. J., Sneed, S. B., Handley, M. J., and Kreutz, K. J.: Monsoonal circulation of the McMurdo Dry Valleys, Ann. Glaciol., 39, 139-145, 2004.

Bromley, A. M.: Weather Observations Wright Valley, Antarctica. New Zealand Meteorological Service: Wellington, New Zealand, 25, 1985.

Brooks, P. D. and Williams, M. W.: Snowpack controls on N cycling and export in seasonally snow covered catchments, Hydrol. Process., 13, 2177-2190, 1999.

Brooks, P. D., Williams, M. W., Walker, D. A., and Schmidt, S. K.: The Niwot Ridge snow fence experiment: Biogeochemical responses to changes in the seasonal snowpack, in: Biogeochemistry of Seasonally Snow Covered Basins, edited by: Tonnessen, K. A., Williams, M. W., and Tranter, M., 228, International Association for Hydrological Sciences, 293-302, 1995.

Brooks, P. D., Williams, M. W., and Schmidt, S. K.: Microbial activity under alpine snowpacks, Niwot Ridge, Biogeochemistry, 32, 93-113, 1996.

Cary, S. C., McDonald, I. R., Barrett, J. E., and Cowan, D. A.: On the rocks: the microbiology of Antarctic cold desert soils, Nat. Rev. Microbiol., 8, 129-138, 2010

Deems, J. S., Fassnacht, S. R., and Elder, K. J.: Interannual consistency of fractal snow depth patterns at two Colorado mountain sites, J. Hydrometeorol., 9, 977-988, 2008.

Doran, P. T., McKay, C. P., Clow, G. D., Dana, G. L., Fountain, A. G., Nylen, T. H., and Lyons, W. B.: Climate observations from the McMurdo Dry Valleys, Antarctica, 1986-2000, J. Geophys. Res.-Atmos., 107, 1-12, 2002.

Edwards, A. C.: Changes in the seasonal snow cover of alpine regions and its effects on soil processes: a review, Quatern. Int., 162-163, 172-181, 2007.

Erickson, T., Williams, M., and Winstral, A.: Persistence of topographic controls on the spatial distribution of snow in rugged mountain terrain, Colorado, United States, Water Resour. Res., 41, W04014, doi:10.1029/2003WR002973, 2005.

Eveland, J., Gooseff, M. N., Lampkin, D. J., Barrett, J. E., and Takacs-Vesbach, C.: Spatial and temporal patterns of snow accumulation and aerial ablation across the McMurdo Dry Valleys, Hydrol. Process., accepted, doi:10.1002/hyp.9407, 2013.

Fountain, A. G., Lyons, W. B., Burkins, M. B., Dana, G. L., Doran, P. T., Lewis, K. J., McKnight, D. M., Moorhead, D. L., Parsons, A. N., Priscu, J. C., Wall, D. H., Wharton, R. A., and Virginia, R. 
A.: Physical controls on the Taylor Valley ecosystem, Antarctica, Bioscience, 49, 961-971, 1999.

Fountain, A. G., Nylen, T. H., Monaghan, A., Basagic, H. J., and Bromwich, D.: Snow in the McMurdo Dry Valleys, Antarctica, Int. J. Climatol., 30, 633-642, 2009.

Gooseff, M. N., Barrett, J. E., Doran, P. T., Fountain, A. G., Lyons, W. B., Parsons, A. N., Porazinska, D. L., Virginia, R. A., and Wall, D. H.: Snow-patch influence on soil biogeochemical processes and invertebrate distribution in the McMurdo Dry Valleys, Antarctica, Arct. Antarct. Alp. Res., 35, 91-99, 2003.

Kennedy, A. D.: Water as a limiting factor in the Antarctic terrestrial environment - a biogeographical synthesis, Arct. Alpine Res., 25, 308-315, 1993.

Keys, J. R.: Air Temperature, Wind, Precipitation and Atmospheric Humidity in the McMurdo Region, Victoria, Antarctic Data Series, Victoria University, Wellington, 25, 1980.

Levy, J. S., Fountain, A. G., Gooseff, M. N., Welch, K. A., and Lyons, W. B.: Water tracks and permafrost in Taylor Valley, Antarctica: Extensive and shallow groundwater connectivity in a cold desert ecosystem, GSA Bulletin, 123, 2295-2311, 2011.

Liston, G. E.: Local advection of momentum, heat and moisture during the melt of patchy snow covers, J. Meteorol., 1705-1715, 1995.

Mott, R., Gromke, C., Grünewald, T., and Lehning, M.: Relative importance of advective heat transport and boundary layer decoupling in the melt dynamics of a patchy snow cover, Adv. Water Res., 55, 88-97, doi:10.1016/j.advwatres.2012.03.001, 2012.

Nylen, T. H., Fountain, A. G., and Doran, P.: Climatology of katabatic winds in the McMurdo Dry Valleys, Southern Victoria Land, Antarctica, J. Geophys. Res., 109, D03114, doi:10.1029/2003JD003937, 2004.

Schimel, J. P., Bilbrough, C., and Welker, J. M.: Increased snow depths affects microbial activity and nitrogen mineralization in two Arctic tundra communities, Soil Biol. Biochem., 36, 217227, 2004.
Schirmer, M., Wirz, W., Clifton, A., and Lehning, M.: Persistence in intra-annual snow depth distribution: 1. measurements and topographic control, Water Resour. Res., 47, W09516, 109, D03114, doi:10.1029/2003JD003937, 2011.

Speirs, J. C., Steinhoff, D. F., McGowan, H. A., Bromwich, D. A., and Monaghan, A. J.: Foehn winds in the McMurdo Dry Valleys, Antarctica: The origin of extreme warming events, J. Climate, 23, 3577-3598, 2010.

Tarboton, D. G. and Luce, C. H.: Utah Energy Balance Snow Accumulation and Melt Model (UEB), Computer model technical description and user's guide: Utah Water Research Laboratory and USDA Forest Service Intermountain Research Station, 1996.

Walker, M. D., Walker, D. A., Welker, J. M., Arft, A. M., Bardsley, T., Brooks, P. D., Fahnestock, J. T., Jones, M. H., Losleben, M., Parsons, A. N., Seastedt, T. R., and Turner, P. L.: Long-term experimental manipulation of winter snow regime and summer temperature in Arctic and alpine tundra, Hydrol. Process., 13, 2315-2330, 1999.

Wall, D. H. and Virginia, R. A.: Controls on soil biodiversity: insights from extreme environments, Appl. Soil Ecol., 13, 137150, 1999.

Winstral, A., Elder, K., and Davis, R. E.: Spatial snow modeling of wind-redistributed snow using terrain based parameters, J. Hydrometeorol., 3, 524-537, 2002.

Witherow, R. A., Lyons, W. B., Bertler, N. A. N., Welch, K. A., Mayewski, P. A., Sneed, S. B., Nylen, T., Handley, M. J., and Fountain, A.: The aeolian flux of calcium, chloride, and nitrate to the McMurdo Dry Valleys landscape: evidence from snow pit analysis, Antarct. Sci., 18, 497-505, 2006.

Zeglin, L. H., Sinsabaugh, R. L., Barrett, J. E., Gooseff, M. N., and Takacs-Vesbach, C. D.: Landscape distribution of microbial activity in the McMurdo Dry Valleys: Linked biotic processes, hydrology, and geochemistry in a cold desert ecosystem, Ecosystems, 12, 562-573, 2009. 